\title{
Addressing Concerns Related to the Use of Ethanol-Blended Fuels in Marine Vehicles
}

\author{
Gregory W. Davis \\ Mechanical Engineering Department, Kettering University, 1700 University Ave., Flint, MI 48504, \\ United States of America \\ e-mail: gdavis@ kettering.edu
}

Cite as: Davis, G. W., Addressing Concerns Related to the Use of Ethanol-Blended Fuels in Marine Vehicles,

J. sustain. dev. energy water environ. syst., 5(4), pp 546-559, 2017, DOI: https://doi.org/10.13044/j.sdewes.d5.0175

\begin{abstract}
Ethanol blended fuels have become increasingly prevalent in the on-road transportation sector due to the benefits they provide in energy security, sustainability and reduced environmental impact. However, ethanol usage has led to material compatibility concerns causing corrosion and degradation in materials that are commonly used in engines and fuel storage/delivery systems. The on-road transportation sector continues to study and develop alternatives to minimize potential material challenges. Although, marine vehicles represent a smaller segment of the transportation sector, they represent many vehicles, particularly in the United States. Concerns related to the use of ethanol blended fuels in the marine environment have been expressed by many individuals and groups. Unfortunately, relatively little work has gone into the study of gasoline mixed with approximately $10 \%$ ethanol usage and potential material incompatibilities in marine engines. The objective of this article is to provide some factual answers to these concerns. In order to understand the extent of material incompatibilities, a literature survey of published material compatibility data and marine engine manufacturer recommendations was conducted. Next field samples of marine fuels were gathered to estimate the extent of ethanol usage in marine gasoline. Finally, samples of new and in-use marine components were exposed to either gasoline mixed with approximately $10 \%$ ethanol or gasoline with $0 \%$ ethanol for 1,960 hours to determine whether gasoline mixed with approximately $10 \%$ ethanol presented degradation beyond that seen with gasoline (gasoline with $0 \%$ ethanol) alone. This work has shown that many marine engine manufacturers have used ethanol compatible materials in current products and that exposure of older marine engine components to gasoline mixed with approximately $10 \%$ ethanol by did not reveal any significant degradation. Finally, marine fuel samples gathered in 2013, reveal that most marine gasoline sold in the Unites States does not contain significant levels of ethanol.
\end{abstract}

\section{KEYWORDS}

Ethanol fuel, Marine engines, Transportation, Ethanol compatibility.

\section{INTRODUCTION}

Renewable fuels, often called biofuels, are becoming widely used throughout the world to decrease dependence upon finite resources such as petroleum to provide energy security and to promote sustainable development $[1,2]$. Ethanol derived from traditional sources such as corn or sugarcane is often called a first-generation biofuel. These sources and methods of production provide the bulk of ethanol used as a fuel in transportation. 
This is due in part to its easy production by fermentation and governmental subsidies and mandates [2]. In the US, gasoline consisting of $10 \%$ ethanol (by volume), or E10 is widely used in automobiles. For example, in 2015 ethanol levels in gasoline accounted for $10 \%$ of all gasoline fuels sold, ensuring that all automobiles frequently used E10 [3]. The use of biofuels has caused some concerns about its effect on food production [4]. As Dias et al. [5] describes that although US corn production grew by 70\% between 2004 and 2007, much of it was used to produce fuel ethanol which consumes $65 \%$ of the corn produced.

When used in engines, the benefits of using ethanol blends have long been recognized. These benefits include increased octane, improved efficiency and power and reduced exhaust emissions. In 1986, Dorn et al. [6] noted the benefits of using ethanol to enhance the octane of gasoline and to reduce the use of petroleum. Further, [6] noted that ethanol can be produced from renewable sources and can reduce some tailpipe emissions levels. Similarly, Hughes et al. [7] also published in 1986, studied the use of ethanol blends to produce high octane fuel for aviation use as a replacement to costly high octane gasoline alone.

In contrast to their benefits, ethanol blends can provide material compatibility and performance concerns as compared to gasoline alone. For example, [6] and [7] noted that ethanol can cause corrosion of metallic and swelling of non-metallic materials, and potentially could present problems due to its miscibility with water. Although ethanol blended fuels are more tolerant of water without separating, if phase separation does occur, it will contain both water and ethanol. Hughes et al. [7] further noted the increased potential for vapor lock with ethanol blended gasoline due to the increased Reid Vapor pressure. This reference also expressed concern regarding the reduced energy content of ethanol blended fuels for use in aviation. Other references, such as Nihalani et al. [8] and Thomas [9] provide detailed studies of the effects of ethanol blended gasoline on elastomeric and fluoro-elastomeric compounds. Cummings [10] further studied the impact of the varied quality of bioethanol blended fuels on the corrosion problems in various fuel system components. The compatibility of various metallic and non-metallic fuel delivery and storage system components to E10 exposure was studied in [11] and [12]. Kass et al. [13] added a comparison of the compatibility of various fuel system components when exposed to E10 or isobutanol blended gasolines.

Much attention has been paid to these problems in engines for on-road, automotive use. The widespread use of ethanol in transportation fuels, however, has led to widespread use of ethanol in off-road engines such as those used in marine vehicles. In the US during 2013, Wallner et al. [14] points out that the recreational use of marine vehicles represented about 10 million units. Further, [14] points out that the recreational marine market does not retire vehicles at the same rate as the on-road automotive sector, leading to significant usage of older vehicles. Compounding this potential problem, marine engines are used with older materials in fuel handling, storage, and fuel delivery. Also, these engines are most often operated in an open-loop control condition where the engine air-fuel mixture is not changed with respect to changes in fuel composition such as levels of ethanol and water in the fuel [15]. This has led to concern for engines used in this environment. Since the ethanol used is hydroscopic, there is an increased likelihood that it could mix with water in the marine environment, potentially causing engine damage [16]. Additionally, Kass et al. [17] found potential concerns with the compatibility of materials commonly used in the fuel infrastructure and in marine vehicle fuel storage to ethanol blended fuels.

Finally, much public misinformation regarding the use of ethanol blended fuels has led to significant public confusion and blame. Unfortunately, this has led people to blame all sorts of engine issues on the use of E10. For example, an insurance company 
conducted a survey of its members and found the following results $(6,000$ respondents) [18]:

- $29 \%$ reported problems that they attributed to the use of E10;

- $91 \%$ expressed concern about possible damage to the engine or fuel system.

A widely referenced article on the internet cautions that E10 is not safe for most boat engines due to ethanol's ability to attract and absorb water [19]. A 2010 Popular Mechanics article (a widely circulated magazine) is also quite negative-even showing the following image (Figure 1).

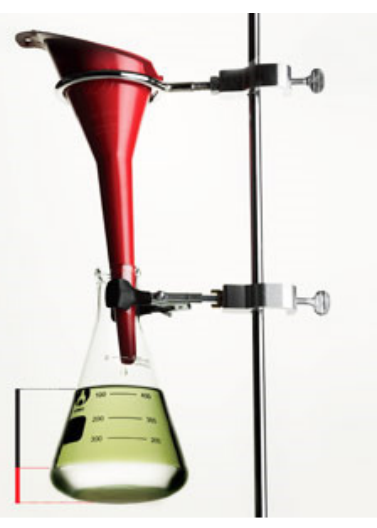

Figure 1. Image from Article Entitled, this flask had 10\% ethanol and high water content, adding just a few drops of water caused all the water and alcohol to separate, forming incombustible glop on the bottom (photo by: Plamen Petkov) (emphasis added) [20]

The purpose of this article is to determine whether ethanol is widely used in marine gasoline and does this usage pose a material compatibility problem for the components used in existing marine vehicles. Factual information needs to be entered into the public discourse in order to educate the public in general, and the policy makers, in particular, about the benefits and challenges of using ethanol blended fuels in the marine sector.

\section{METHODS}

To clarify the effect that ethanol (E10) plays in marine vehicles, a review of the published information regarding the compatibility of metallic and non-metallic materials with ethanol and major marine engine manufacturer recommendations was conducted. This was followed by a field survey of the actual ethanol levels found in marine fuels available in the state of Michigan, US, during the 2013 recreational boating season. Finally, to assess compatibility of materials used in marine fuel systems, samples of new and in-use marine components were procured and tested for compatibility with exposure to E10.

\section{MATERIAL COMPATIBILITY WITH ETHANOL}

Major marine manufacturers warrantee the use of E10 in their systems. These manufacturers include Mercury Marine [21], Honda Marine [22] and Yamaha Outboards [23]. Determining an exact date of boat engine certification with ethanol is rather difficult, but most manufacturers switched during the late 1980s or early 1990s. Therefore, all newer boat engines are certified to operate using E10 fuel. Most manufacturers recommend changing fuel filters and possibly fuel tanks (on 1980 systems) when first beginning to use E10 on an existing boat.

Some materials commonly used with older gasoline-powered vehicles are not compatible with ethanol. These materials degrade when in contact with ethanol, which may lead to leaks or fuel system contamination [24]. Fortunately, there are many 
alternatives for these incompatible materials, which have been largely replaced in modern on-road vehicles. Unfortunately, less information is known about the materials used in the marine transportation sector, therefore, it is difficult to know which models of marine vehicles are incompatible without testing.

Ethanol material compatibility is discussed below for metallic and non-metallic compounds.

\section{Metallic substances}

Metallic substances that are degraded by ethanol include zinc, brass, aluminum, and lead-plated steel. These materials can react with ethanol, partially dissolving in the fuel. This can contaminate the fuel system, leading to clogged fuel filters and injectors, which in turn cause poor marine vehicle drivability.

Unfortunately, many vehicles use aluminum in fuel delivery systems to save weight, including in the fuel pump, lines, fuel rail, and fuel pressure regulator. Aluminum can be safely used if it is hard anodized or nickel-plated.

Other metallic compounds that are resistant to ethanol include un-plated steel, stainless steel, black iron, and bronze.

\section{Nonmetallic substances}

Nonmetallic materials that degrade when in contact with ethanol include natural rubber, polyurethane, cork gasket material, leather, Polyvinyl Chloride (PVC), polyamides, methyl-methacrylate plastics, and certain thermoset plastics.

Nonmetallic materials that are resistant to ethanol degradation include nonmetallic thermoset reinforced fiberglass, thermoplastic piping, Buna-N, neoprene rubber, polypropylene, nitrile, Viton, and Teflon. The ethanol tolerance of these materials varies with grade or compound as well as the ethanol content of the fuel. Modern vehicles use ethanol-tolerant materials for gaskets and O-rings, for example, most automakers now use Viton O-rings to seal their fuel injectors.

Older marine vehicles often use reinforced fiberglass fuel storage tanks. These have often been cited as failing due to exposure to E10 [25], however, reinforced fiberglass is listed by the US Department of energy as an ethanol-resistant compound! This conflicting information is confusing for the boat owner.

Further adding to the confusion as to whether ethanol is safe for marine fuel systems comes in the form of marine engine manufacturer fuel additives. Some have been reported as containing alcohols. For example, Mercury Marine Fuel Additive is said to contain 15\% isopropyl alcohol, while Evinrude $2+4$ additive contains $95 \%$ isopropyl alcohol [26]. Thus, the use of alcohols in gasoline fuels is not new, and to some extent, has been used to improve engine operation.

\section{DETERMINATION OF ETHANOL CONTENT IN MARINE GASOLINE}

Kettering University anonymously sampled and tested commercially available fuel from a random selection of marinas located in the state of Michigan, US, to get an indication of the ethanol content of the fuel that boaters are likely to purchase during the boating season. Twenty-five gasoline fuel samples were collected from marina and recreation fuel pumps throughout the state of Michigan from July 25 to August 10, 2013. Thirteen samples were from marinas located in close proximity to the Great Lakes, while 12 samples were collected from fuel stations located at or near marinas on inland lakes. Of the Great Lakes marinas, 9 of the marinas are considered to be large, while 4 were of medium size. Among inland marinas, 2 were large facilities, 8 were medium-sized, and 2 were small. All of the marinas except two medium-sized inland marinas, claimed to sell "ethanol-free" fuel, or E0. 
The E0 sold was typically advertised as 89-90 octane and occasionally labelled as "recreation fuel". A typical marina gasoline storage tank can be seen in Figure 2. The fuel from each location was dispensed into legal fuel canisters and then transferred to sample bottles as seen below.
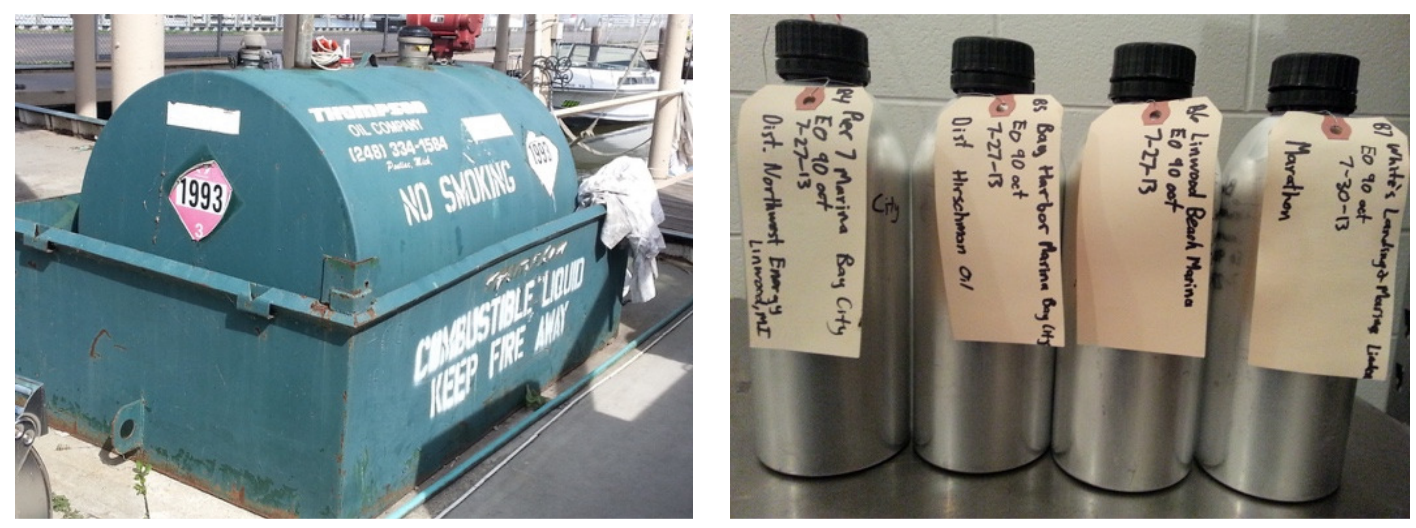

Figure 2. Marina fuel tank (left) and fuel sample bottles (right)

Ethanol content testing was performed for the 25 samples in the Advanced Engine Research Laboratory at Kettering University on August 12, 2013. A Siemens flex-fuel sensor, shown in Figure 3, was used in all testing. The sensor output was calibrated using $100 \%$ ethanol and Stoddard solvent. Stoddard solvent is commonly used as a standard substitute for petroleum based gasoline. Three tests of each fuel sample were then conducted. The protocol consisted of measuring the fuel and purging the sensor with Stoddard solvent between each test.

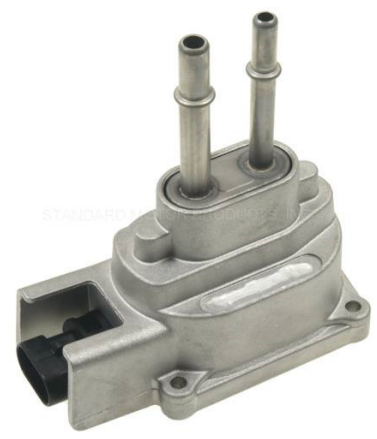

Figure 3. Siemens flex-fuel sensor

Of the 23 samples advertised as E0, 16 samples contained no ethanol, while 7 contained very low levels of up to $0.4 \%$ ethanol. Of the 7 samples that contained low levels of ethanol, 5 were Great Lakes locations, 2 were from inland marinas. These samples were also distributed from different size marina fuel stations: 3 were large, 3 were of medium size, and one was small. The low level of ethanol found suggests that all 23 samples can be considered ethanol-free gasoline.

The two samples not advertised as ethanol-free contained approximately $9 \%$ ethanol. These samples were collected from marinas located on inland lakes in southeastern Michigan.

In response to the preference of boaters to purchase ethanol-free gasoline, the majority of boat marinas are selling E0 gasoline to their customers. Only two marinas sampled out of twenty-five total did not advertise their gasoline as ethanol-free. These two marinas-located on inland lakes in southeastern Michigan-contained about 9\% ethanol. 
This demonstrates that most boaters are not actually using E10 if they fill their boats at marinas advertising E0. This is interesting in that if most boats are not fueled with E10, why is ethanol blamed for many fuel system problems?

\section{MARINE FUEL SYSTEM MATERIAL COMPATIBILITY TESTING OF E10}

To assess compatibility of materials used in marine fuel systems, samples of new and in-use marine components were procured. To test a wide range of marine fuel system components, a range of ages and component types were studied. Marine fuel system components ranged from fuel storage tanks, delivery tubing, to engine carburettors. The ages of the components ranged from 1984 to 2013. Further, these components were manufactured by many different major producers of marine vehicles and components.

These components were then sectioned into samples for testing and initial inspection. In order to assess the effects of the E10 on these materials as compared with the effects of exposure to E0 (gasoline), an experiment was conducted to expose identical components to each fuel under identical conditions. Both fuel samples were acquired from commercial suppliers on the same date to minimize differences in aging or formulation.

To simulate repeated fuel exposure and enhanced aging, the samples were repeatedly sprayed with fuel, followed by a timed air-drying. Intermittent exposure to fuel was chosen to better simulate the filling and emptying of tanks, carburetor bowls, and fuel lines and to encourage faster oxidation due to the periods of drying and exposure to air. This more severe testing should help to rapidly uncover material incompatibilities as compared to constant submersion in fuel.

To allow for intermittent fuel flow, an electronic control system was implemented to run the fuel pumps and expose the samples to fuel drip for 10 minutes each hour, followed by a 50-minute drying period of exposure to air (cycle of 10 minutes on/50 minutes off).

The total duration of the test was 1,960 hours and the total fuel drip run time was 327 hours. At the conclusion of the test, the material samples were removed from the parts washers for final inspection.

\section{Experimental apparatus}

To prevent the introduction of material issues related to the experimental apparatus, only ethanol compatible materials were used for the test equipment. Two stainless steel parts washers (shown in Figure 4), one for each of E0 and E10, were used to house the material samples, fuels, and fuel drip supply systems. The fuel supply plumbing and test piece layout can be seen in the right-hand photograph. Low-pressure automotive fuel pumps were used to recirculate fuel from the bottom of the parts washers into tubing perforated with small holes that allowed light streams of fuel to drip directly onto the material samples. The fuel then drained from the parts to the bottom of the parts washer for circulation again.
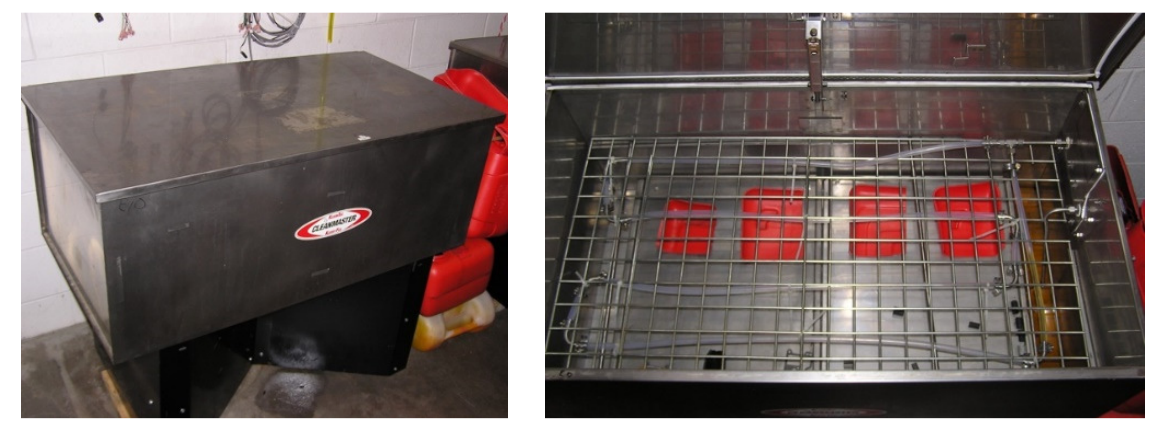

Figure 4. Stainless steel parts washer exterior (left) and interior revealing fuel plumbing and sample layout 


\section{Marine fuel storage tank samples}

The marine vehicle fuel storage tank samples were chosen to represent a timeframe spanning from 1990 to 2000 . This was done because of concern with the danger of fuel tank failures when exposed to E10. These previously used fuel storage tanks were then sectioned and initially inspected as shown in Figure 5. As is shown, the tanks were all in relatively good shape, but each had some evidence of fuel staining.

At the completion of testing, the tanks were removed and then re-inspected as shown in Figure 6. No differences were observed between the E0 and E10 fuel tank material samples in relative pliability. However, there was more of an accumulation of dirt in the recesses of the E10 parts where they were exposed to the fuel drip. Ethanol is a solvent and it is apparent the E10 fuel cleaned dirt from all the samples and redeposited it in the recesses of the tank samples.

It is also notable that the 1990 Mercury fuel tank sample suffered no degradation throughout the test, despite Mercury's suggestion that 1990 and older outboard engines should have "frequent inspections of all fuel-system components". This particular fuel tank from 1990 behaved the same as later-model fuel tanks when exposed to E10.
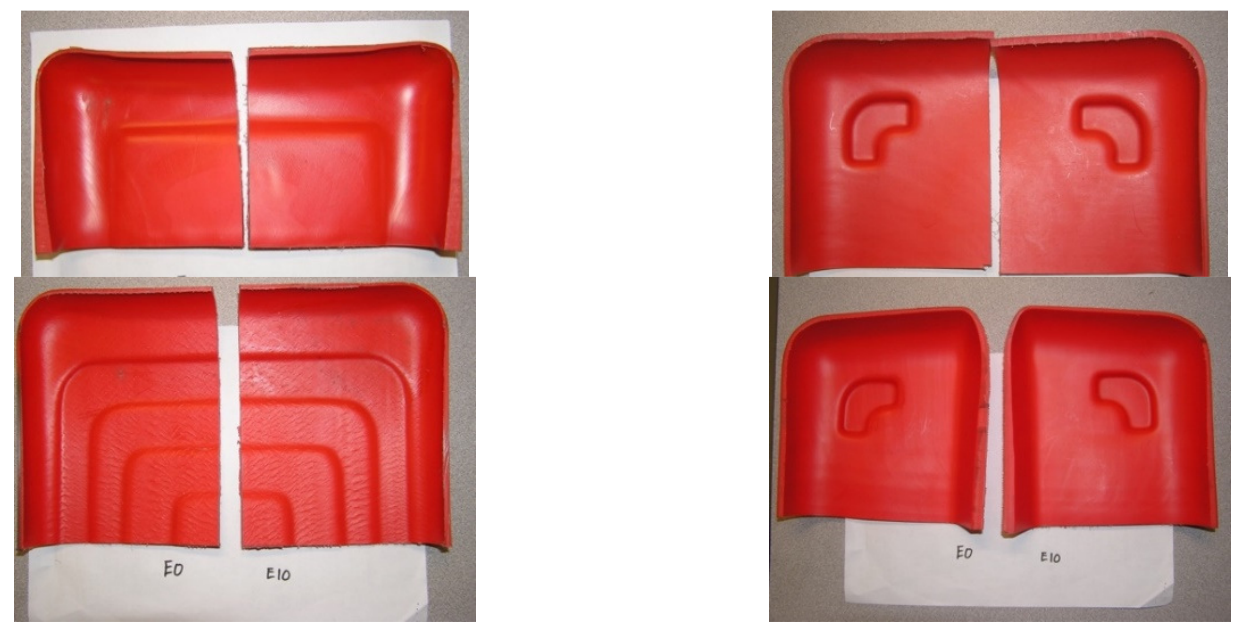

Figure 5. Initial inspection of marine fuel storage tank samples (clockwise from top left): 1990 Mercury, 1995 Mercury, 2009 Neptune, 2011 Yamaha
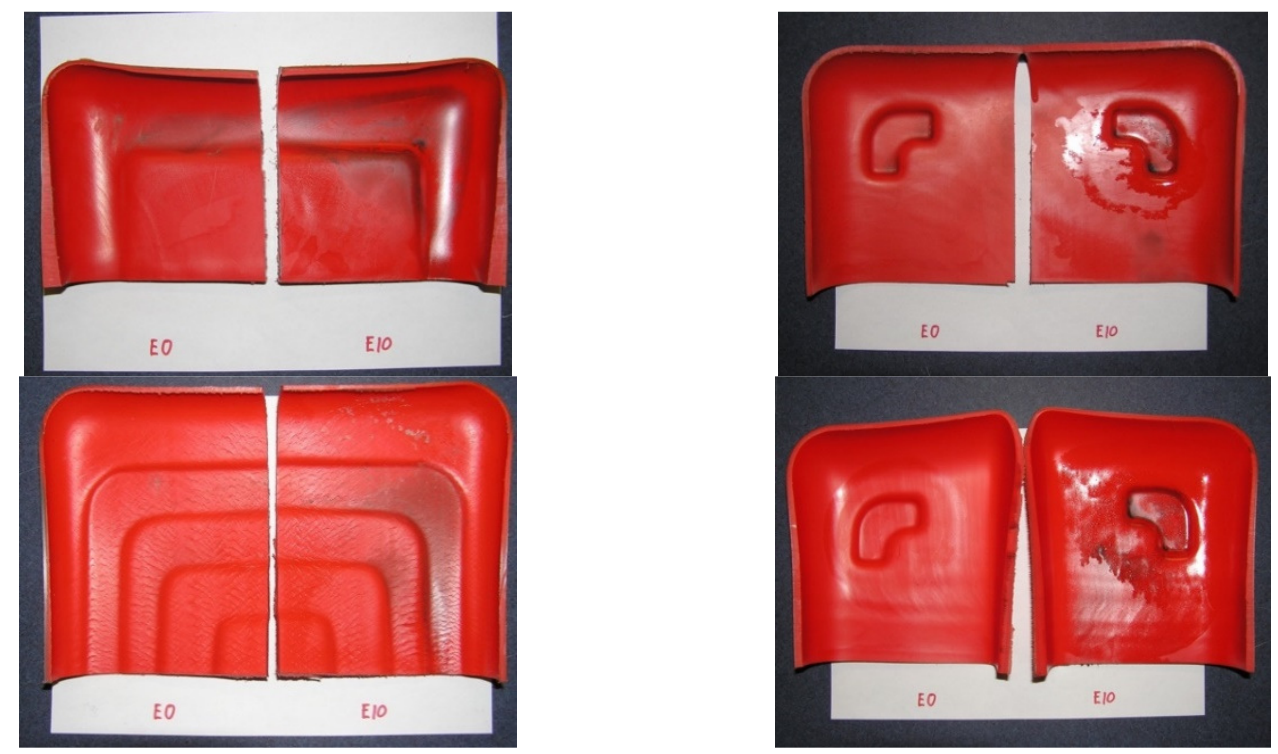

Figure 6. Post-test inspection of fuel tank samples (clockwise from top left): 1990 Mercury, 1995 Mercury, 2009 Neptune, 2011 Yamaha 


\section{Marine fuel transport tubing samples}

A broad distribution of fuel line samples was obtained representing samples from 1989 through 2013 (new). The new 2013 fuel line sample was chosen as it is represented as meeting full ethanol compatibility (SAE 30R7-KX). SAE 30R7 standard fuel and oil hose is approved for use with gasoline blends of ethanol and E85, and as such, this sample was chosen as an experimental control that had not been previously aged by marine use. These fuel line samples were then split so that both the inside and outside of the tubes could be exposed to the compatibility testing. Further, this split allowed for easy visual inspection of the parts. The initial inspection results are shown in Figure 7.

After testing, the samples were again inspected with the results shown in Figure 8. Like the fuel tank material samples, fuel line samples also showed no correlation between age and degradation from exposure to E10. No differences were discerned between the E0 and E10 samples of the 1989 Yamaha and 1996 Johnson fuel lines. However, differences were observed between E0 and E10 samples of the 2000 Mercury and 2013 SAE 30R7-KX fuel line samples.

Figure 9 shows the 2000 Mercury fuel line samples which were cut in the axial direction. While there was no noticeable degradation of either sample, the E10 sample showed a light-colored material accumulation on the inner diameter that was easily removed by touch. The E10 sample is also significantly more pliable by hand in the radial direction than the E0 sample, which is harder to manipulate by hand. Unfortunately, these samples are too thin to test for durometer A-scale hardness.

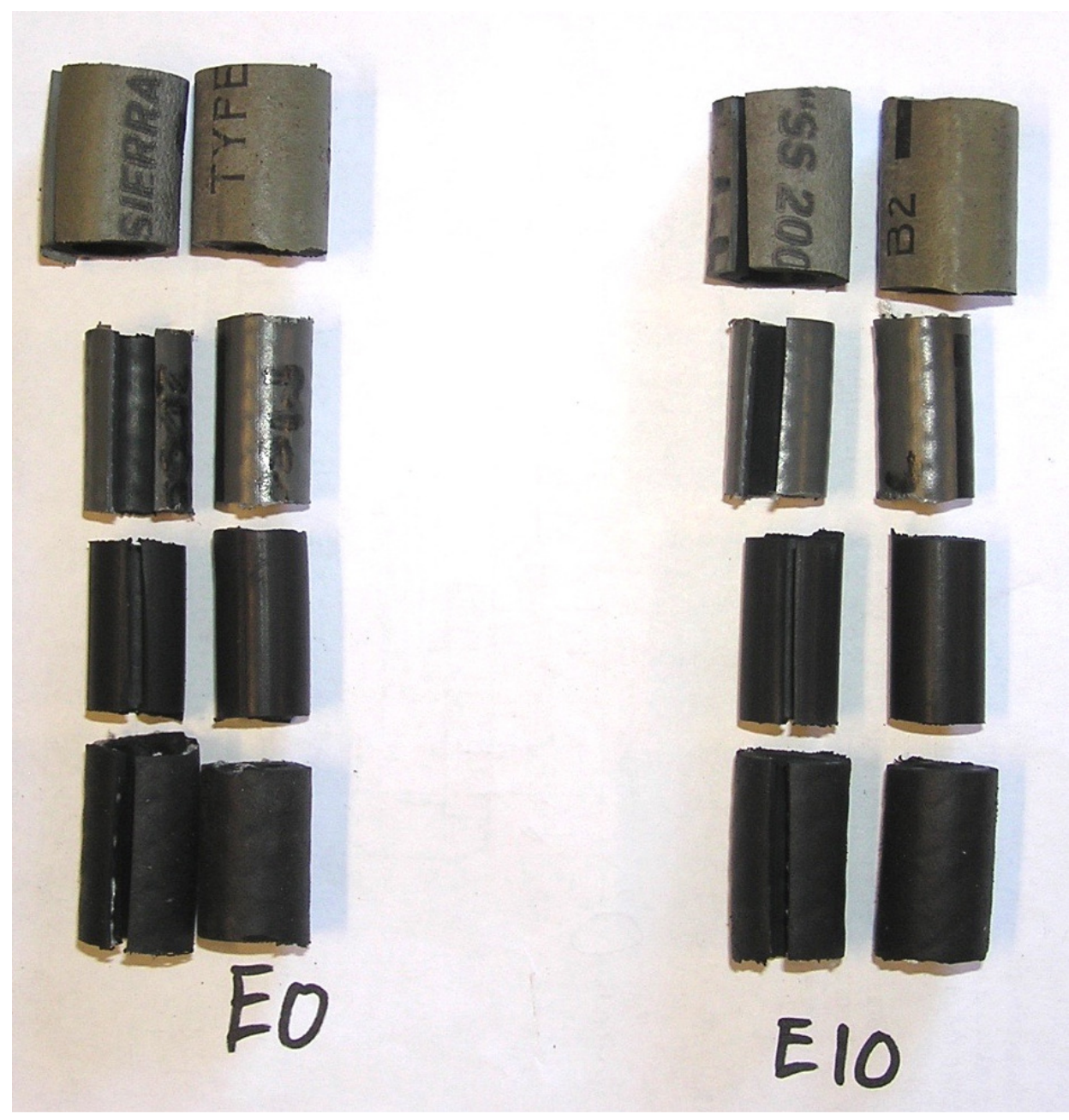

Figure 7. Initial inspection of marine fuel line samples (from top): 1996 Johnson, 2000 Mercury, 1989 Yamaha, 2013 SAE 30R7-KX 


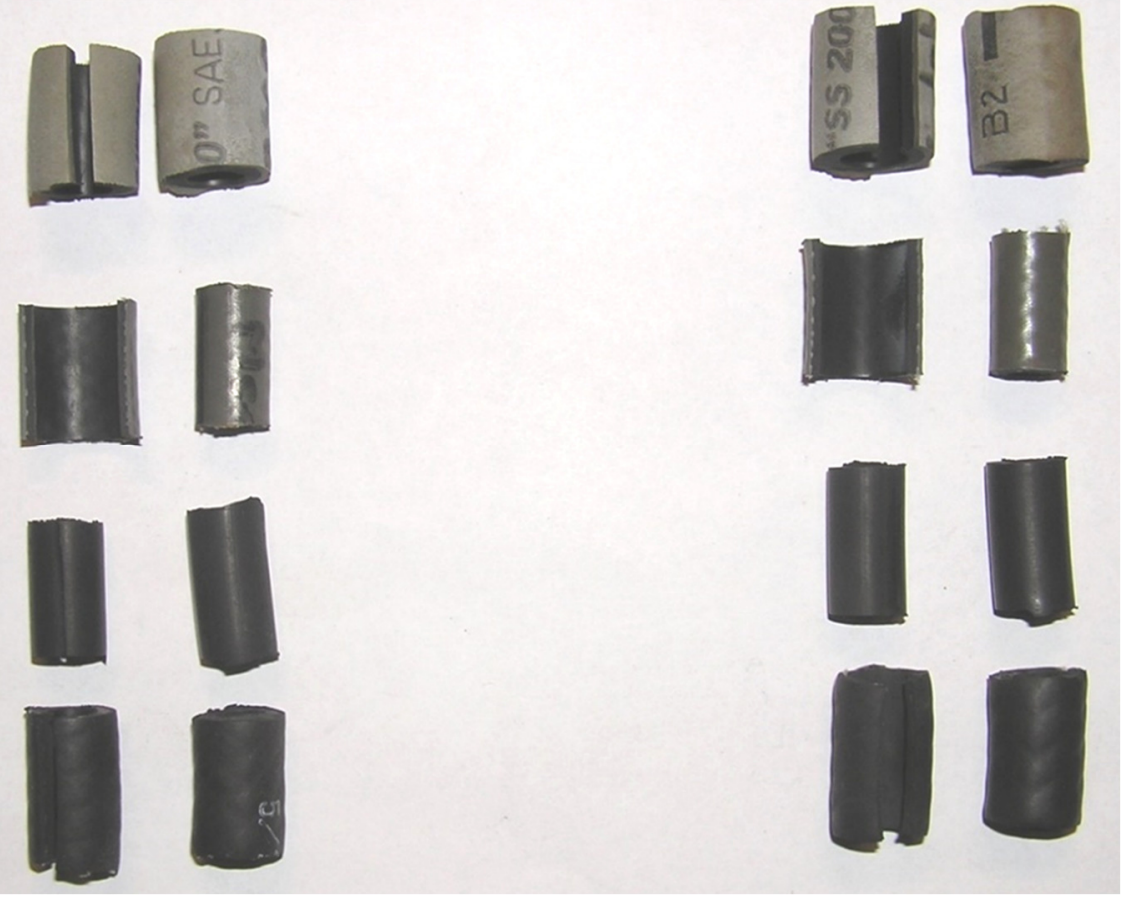

Figure 8. Post-test inspection of marine fuel line samples (from top): 1996 Johnson, 2000 Mercury, 1989 Yamaha, 2013 SAE 30R7-KX (E0 samples on left)
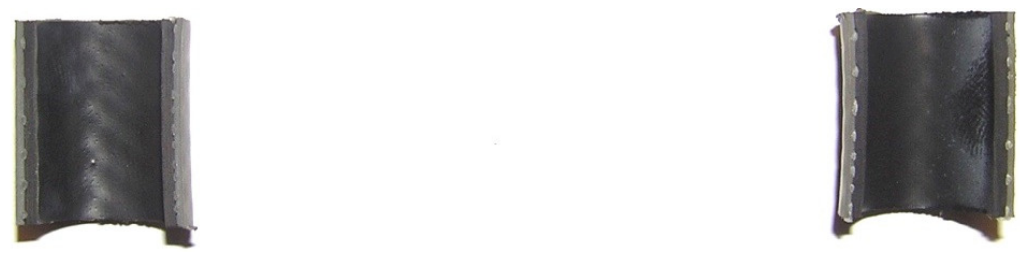

Figure 9. Post-test inspection of 2000 Mercury fuel line revealing some deposit on

E10 sample (right)

The 2013 SAE 30R7-KX fuel line sample that was split axially for direct exposure of the inner surface to the fuel drip exhibited cracking of the interior in the axial direction with exposure to E10, while the E0 sample showed no cracking (Figure 10). No cracking of the interior was observed on the hose samples that were not cut in the axial direction. Perhaps the structure of the hose interior was compromised by the axial cut, leaving it prone to degradation due to the loss of the compressive force usually applied by the spiral synthetic material reinforcement located in the wall. While SAE 30R7 hose is approved for use with ethanol blended fuels, SAE 30R9 hose, with a thin tube of fluoroelastomer at the inner diameter is a better choice for use with most fuels.
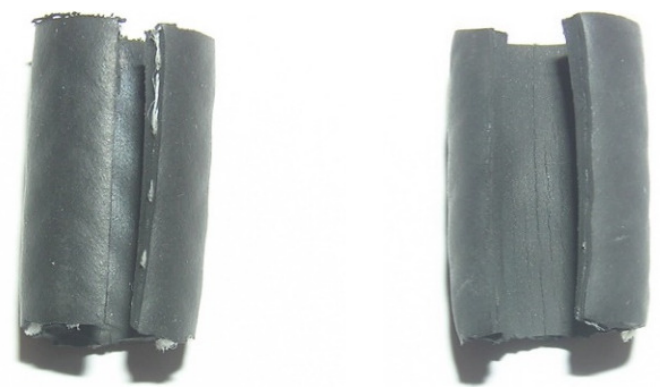

Figure 10. Post-test inspection of 2013 SAE 30R7-KX fuel line revealing longitudinal crack on E10 sample (right) 


\section{Marine fuel primer "Squeeze" bulb sample}

One primer squeeze bulb, from a 1989 Yamaha outboard engine, was available for the test and is pictured in Figure 11. This was the only sample material sufficiently thick to perform a durometer A-scale hardness test, with a pre-test value of 87 .

After testing, the 1989 Yamaha primer squeeze bulb, like the 2000 Mercury fuel line discussed above, exhibited softening of the sample with exposure to E10 as compared to the sample exposed to E0. Compared to the pre-test sample, the post-test E10 sample was significantly easier to manipulate by hand. Post-test durometer A hardness testing confirms the subjective observation as the bulb sample which was exposed to E10 decreased from a durometer A-scale value of 87 down to a level of 77 . No other changes were observed to have taken place, as can be seen in Figure 12.
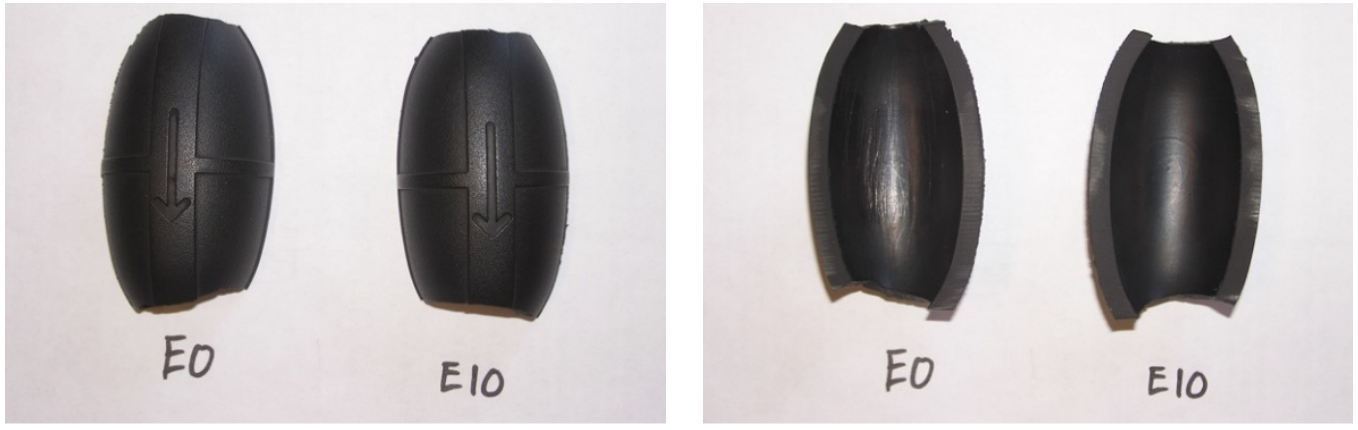

Figure 11. Initial inspection of 1989 Yamaha outboard squeeze bulb
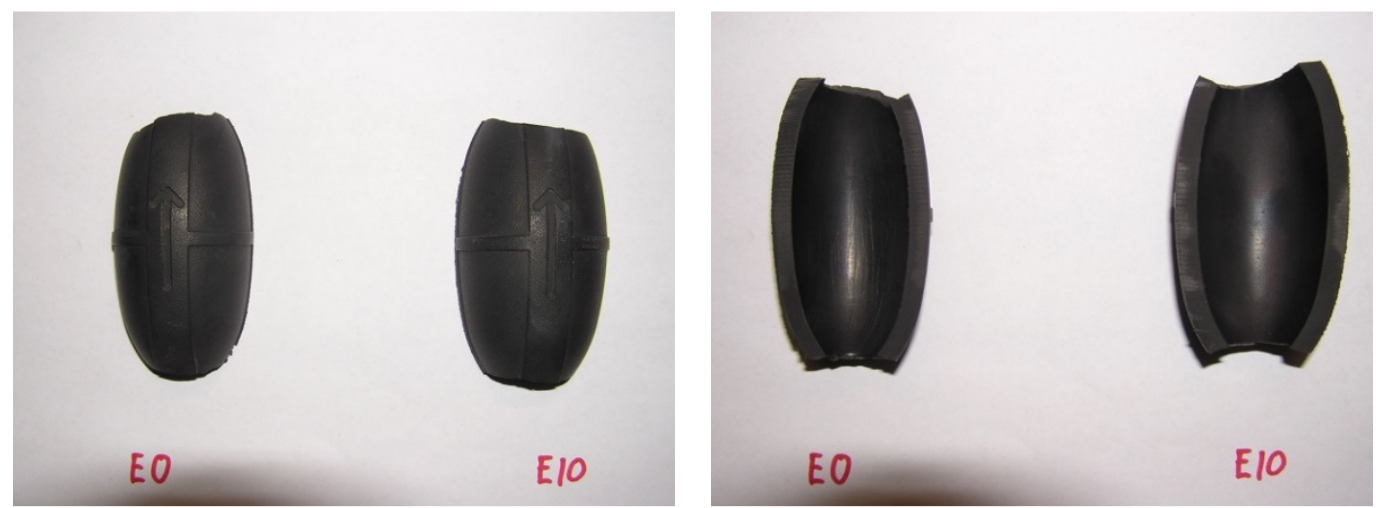

Figure 12. Post-test inspection of the 1989 Yamaha squeeze bulb

\section{Marine engine carburetor component samples}

Two sets of carburetor bowl gaskets and floats, from 1984 Mercury outboard engines, were available for the test and are pictured in Figures 13 and 14.

Initial inspection of the carburetor gaskets from the 1984 Mercury outboard engine showed some discoloration from use as shown in Figure 13. After testing the gaskets were inspected as shown in Figure 14. No noticeable degradation or differences in condition were observed for the E0 and E10 samples. Additionally, there was no measurable difference in hardness or flexibility between the two post-test samples.

The 1984 Mercury carburetor floats were also inspected before and after testing. Testing did not reveal any difference in degradation between the E0 and E10 samples (shown in Figures 15 and 16). The surface roughness of the floats, however, did lead to more dirt and staining due to the solvent action of the E10 fuel in cleaning and then redistributing the dirt and grime during testing. This staining gives the E10 floats a much darker appearance on the bottom surfaces as shown in the right-hand photographs of Figure 16. 

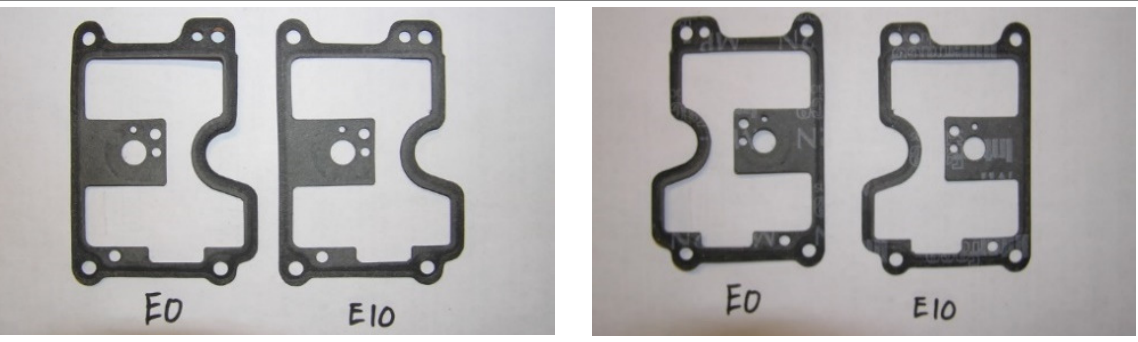

Figure 13. Initial inspection of 1984 Mercury outboard carburetor bowl gaskets
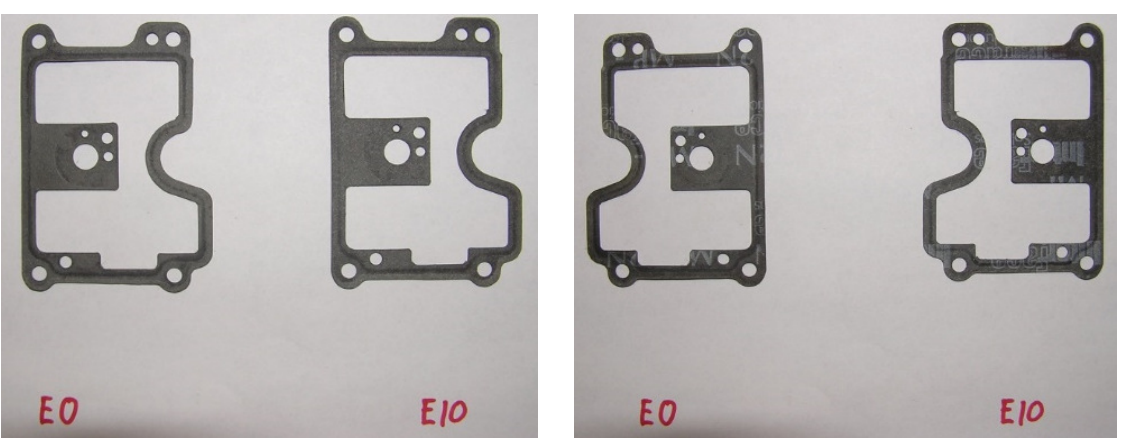

Figure 14. Post-test inspection of 1984 Mercury outboard carburetor bowl gaskets

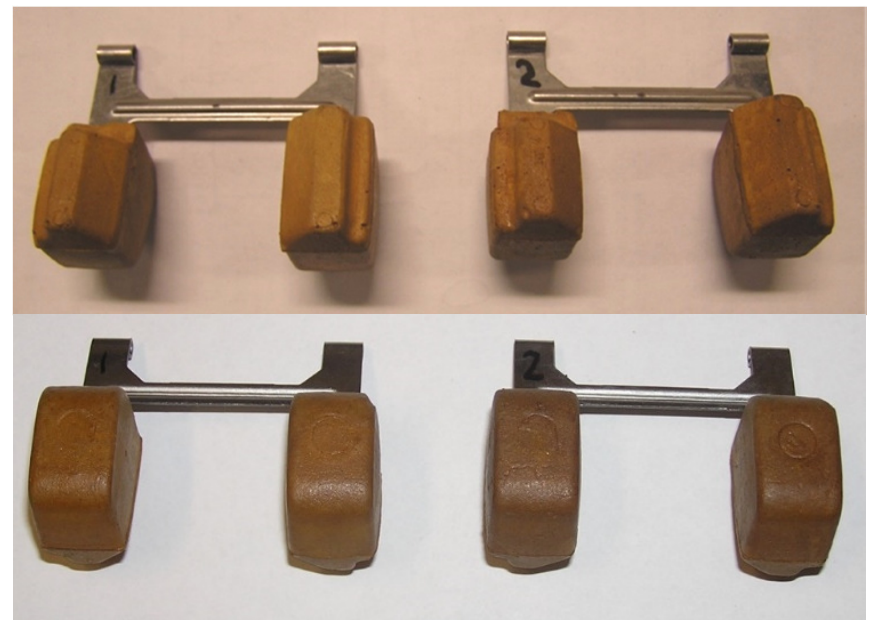

Figure 15. Initial inspection of 1984 Mercury outboard carburetor floats (E0 on left, E10 on right)

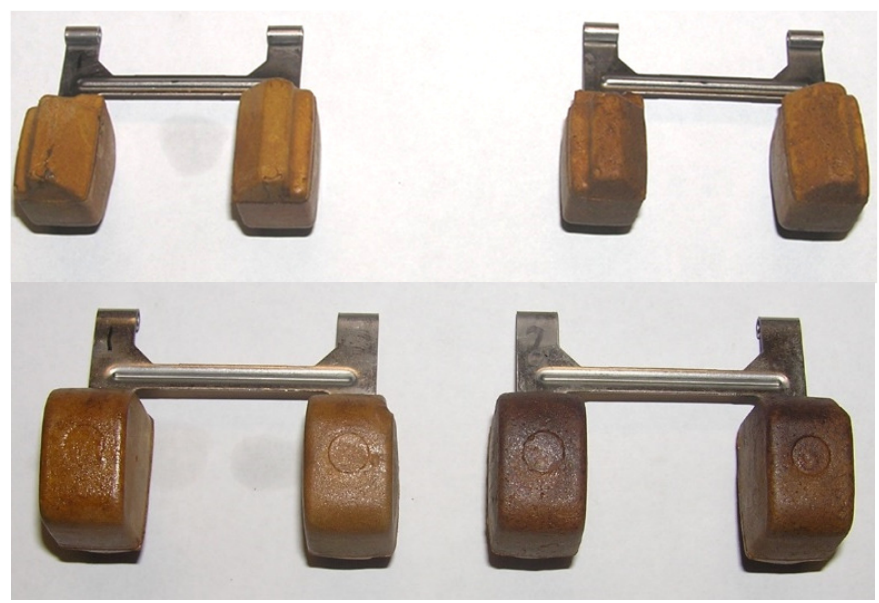

Figure 16. Post-test inspection of 1984 Mercury outboard carburetor floats (E0 on left, E10 on right) 


\section{Post-testing inspection of stainless steel parts washers used for testing}

Due to the staining present on some of the samples after the exposure testing, an inspection of the two stainless steel parts washers used for testing was conducted. Figure 17 shows the difference in the amount of dirt remaining in the E0 and E10 parts washers after the removal of the 1990 Mercury fuel tank material samples. The solvent action of the ethanol in the E10 fuel cleaned, then redistributed significantly more matter from the samples than did the E0 fuel.
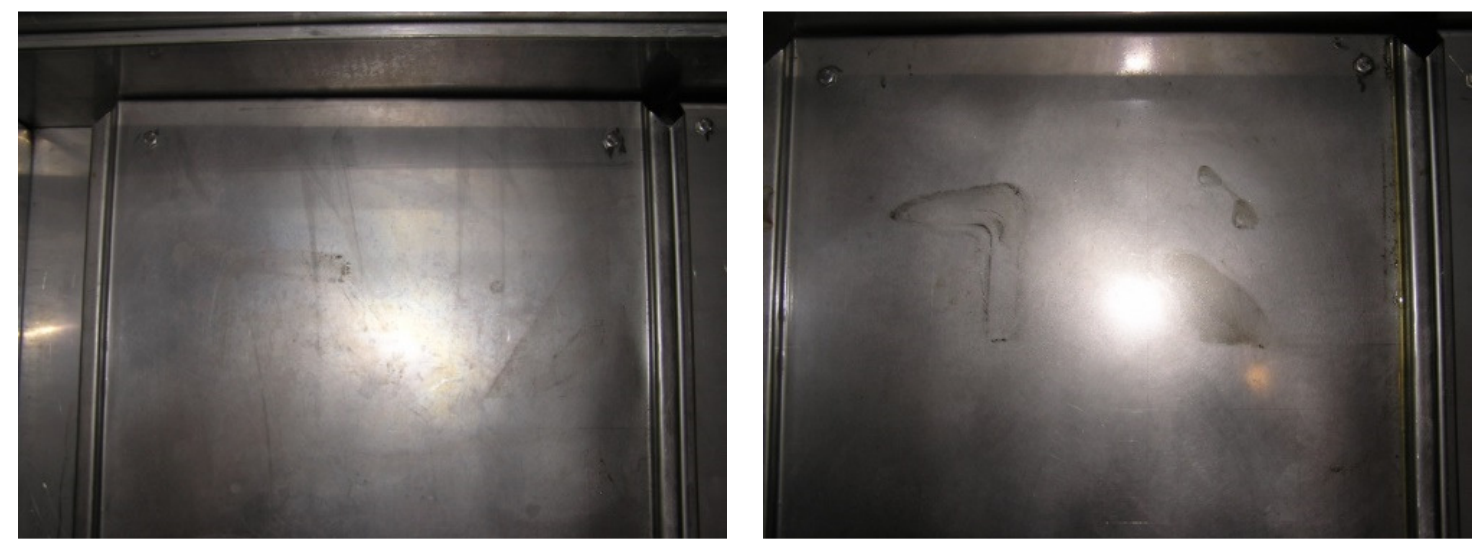

Figure 17. Post-test inspection of stainless steel parts washers used for testing (E0 on left, E10 on right) (note the additional staining in the E10 unit, right)

\section{CONCLUSIONS}

The results of this research demonstrate that, although E10 fuel is widely used in the on-road automobile transportation sector, as of 2013, its use is still very limited in the marine sector. Sampling of fuel from various size marinas located in very different areas of the state of Michigan, US, revealed that all fuel advertised as "ethanol free" had very little to no ethanol content. Interestingly, many operators of marine vehicles still accuse ethanol of causing problems in marine use even though this study shows that the use of E10 in marine vehicles is very unlikely.

The E10 exposure testing of marine fuel system components showed that the marine fuel system materials generally did not show significant degradation when exposed to E10 ethanol blended gasoline. After 1,960 hours of testing, no samples were directly compromised by E10 compared to E0 in a way that would decrease their functionality. This compares well with the recommendations and warrantees provided by major marine engine manufacturers for new products. However, some components and materials did exhibit some changes after exposure indicating that further testing of these materials should be conducted.

The guidelines provided by marine manufacturers regarding the switch from E0 to E10 fuel in boats include replacing fuel filters and looking for the transfer of sludge from the fuel storage system to the fuel filters and lines. These precautions are well founded as the results of the ethanol exposure testing clearly demonstrated the ability of the ethanol in the fuel to act as a solvent. Compared to E0, E10 removed foreign matter from components and redistributed it in other areas.

It can be concluded from this work, that most in-use marine engines should not be adversely affected with the use of E10 and that many of the reported concerns seem to be not well-founded. Caution should, however, always be exercised when dealing with fuel system components. Inspections should be routinely performed, and any lines that show bulging or cracking should be immediately replaced. 


\section{NOMENCLATURE}

\author{
Abbreviations \\ E0 \\ E10 \\ SAE 30R7-KX
}

SAE 30R9
Gasoline with $0 \%$ ethanol

Gasoline mixed with approximately $10 \%$ ethanol by volume

SAE International standard designation for low pressure fuel hose with resistance to a variety of fuels (not recommended for biodiesel) Designed specifically for fuel injection systems, with a thin tube of fluoroelastomer at the inner diameter to provide lower permeation for most fuels

\section{ACKNOWLEDGEMENT}

This project could not have been completed without the dedicated efforts of many people, some of these are acknowledged here: Matt Birt \& Mike Cox and Kettering University students. These students conducted much of the ethanol marine testing; Mr. Ray Rust and Mr. Clint Lee, Senior Mechanical Engineering Technicians. These individuals provide much "behind the scenes" help and support that is vital to the success of these projects, Kettering University Clean Snowmobile and Formula SAE Teams. These student teams, consisting of approximately 60-80 students, work diligently each year, often without receiving course credit to develop and learn about automotive engineering - sponsors. We have many sponsors, both large and small who provide material and technical support to our teams. Some of these sponsors include the Corn Marketing Program of Michigan, Yamaha Motorsports, Emitec, and many more.

\section{REFERENCES}

1. Hammerschlag, R., Ethanol's Energy Return on Investment: A Survey of the Literature 1990-Present, Eniron. Sci. Technology, Vol. 40, No. 6, pp 1744-1750, 2006, https://doi.org/10.1021/es052024h

2. Energy Independence and Security Act of 2007 (EISA), EPA 40 CFR Part 80, Regulation of Fuels and Fuel Additives - Renewable Fuels Standard (RFS-II), March 26, 2010.

3. U. S. Energy Information Agency, How much Ethanol is in Gasoline, and how does it affect Fuel Economy?, http://www.eia.gov/tools/faqs/faq.cfm?id=27\&t=10, [Accessed: 25-May-2016]

4. Chiodi, A., Deane, P., Gargiulo, M. and Gallachóir, B., The Role of Bioenergy in Ireland's Low Carbon Future - is it Sustainable?, J. Sustain. Dev. Energy Water Environ. Syst., Vol. 3, No. 2, pp 196-216, 2015, https://doi.org/10.13044/j.sdewes.2015.03.0016

5. Dias, M. A. P., Haddad Alves, A. S. and Vianna, J. N. S., A Pathway to Energy and Food Security with Biodiesel, J. Sustain. Dev. Energy Water Environ. Syst., Vol. 4, No. 3, pp 242-261, 2016, https://doi.org/10.13044/j.sdewes.2016.04.0020

6. Dorn, P., Mourao, A. M. and Herbstman, S., The Properties and Performance of Modern Automotive Fuels, Society of Automotive Engineers, Tech. Paper 861178, 1986, https://doi.org/10.4271/861178

7. Hughes, L. and Kimberlin, R., A Feasibility Study on the use of Ethanol/Automotive Gasoline Blends in General Aviation Aircraft, Society of Automotive Engineers, Tech. Paper 861598, 1986.

8. Nihalani, I., Paulmer, R. D. A. and Rao, Y. P., Compatibility of Elastomeric Materials with Gasohol, SAE International, SAE Technical Paper 2004-28-0062, 2004, https://doi.org/10.4271/2004-28-0062

9. Thomas, E. W., Fluoroelastomer Compatibility with Bioalcohol Fuels, SAE Int. J. Fuels Lubr., Vol. 2, No. 1, pp 462-473, 2009, https://doi.org/10.4271/2009-01-0994 
10.Cummings, J., Effects of Fuel Ethanol Quality on Vehicle System Components, SAE International, SAE Technical Paper 2011-01-1200, 2011, https://doi.org/10.4271/2011-01-1200

11.Vyas, D., Bawase, M. A. and Saraf, M. R., Study of Compatibility of Metals used in Fuel System of Gasoline Engine with E10 and E20, SAE Technical Paper 2013-01-2880, 2013, https://doi.org/10.4271/2013-01-2880

12.Bawase, M. A., Baikerikar, A. and Saraf, M. R., Material Compatibility of Elastomers and Plastics in Ethanol-blended (E10) Gasoline, SAE Technical Paper 2013-26-0077, 2013, https://doi.org/10.4271/2013-26-0077

13.Kass, M., Theiss, T., Pawel, S., Baustian, J. et al., Compatibility Assessment of Elastomer Materials to Test Fuels Representing Gasoline Blends Containing Ethanol and Isobutanol, SAE Int. J. Fuels Lubr., Vol. 7, No. 2, pp 445-456, 2014, https://doi.org/10.4271/2014-01-1462

14.Wallner, T., Ickes, A., Wasil, J., Sevik, J. et al., Impact of Blending Gasoline with Isobutanol Compared to Ethanol on Efficiency, Performance and Emissions of a Recreational Marine 4-Stroke Engine, SAE Technical Paper 2014-01-1230, 2014, https://doi.org/10.4271/2014-01-1230

15.Wasil, J., McKnight, J., Kolb, R., Munz, D. et al., In-Use Performance Testing of Butanol-Extended Fuel in Recreational Marine Engines and Vessels, SAE Technical Paper 2012-32-0011, 2012, https://doi.org/10.4271/2012-32-0011

16.Wasil, J. and Wallner, T., Gaseous and Particulate Emissions using Isobutanol-Extended Fuel in Recreational Marine Two-Stroke and Four-Stroke Engines, SAE Int. J. Fuels Lubr., Vol. 7, No. 3, pp 1062-1068, 2014, https://doi.org/10.4271/2014-32-0087

17.Kass, M., Janke, C., Theiss, T., Baustian, J. et al., Compatibility Assessment of Plastic Infrastructure Materials with Test Fuels Representing E10 and iBu16, SAE Int. J. Fuels Lubr., Vol. 8, No. 1, pp 95-110, 2015, https://doi.org/10.4271/2015-01-0894

18.Hagerty Insurance, https://www.hagerty.com/articles-videos/articles/2013/08/19/ living-with-ethanol, [Accessed: 25-May-2016]

19.Fuel Testers, http://www.fuel-testers.com/e10_gas_not_safe_for_marine_engine.html, [Accessed: 25-May-2016]

20.Allen, M., Can E15 Gasoline Really Damage Your Engine?, Popular Mechanics, http://www.popularmechanics.com/cars/alternative-fuel/biofuels/e15-gasoline-damageengine, 2010, [Accessed: 25-May-2016]

21.Mercury Marine, http://www.mercurymarine.com/service-and-support /customer-support/faqs/warranty/, [Accessed: 07-June-2013]

22.Honda Marine Division, http://marine.honda.com/owners/fuel-recommendations, [Accessed: 23-July-2013]

23.Yamaha Motorsports Division, http://www.yamahaoutboards.com/ owner-resources/FAQ/ethanol-topics, [Accessed: 23-July-2013]

24.U.S. Department of Energy, Handbook for Handling, Storing, and Dispensing E85, DOE/GO-1002001-956, 2005.

25.Hagerty Insurance, Important News for Boat Owners, 26 October 2006, https://www.hagerty.com/articles-videos/articles/2006/10/26/important-news-for-boat-o wners, [Accessed: 25-May-2016]

26.Material Safety Data Sheet, EJFC16-Evinrude Johnson Fuel Conditioner, MSDS 775614. 